\title{
RINDTARINDIST NIMISÕNAFRAASI OSANA
}

\author{
MATI ERELT
}

\begin{abstract}
Annotatsioon. Artiklis vaadeldakse adjektiivatribuudi mitmuse kasutust, kui atribuut laiendab ainsuslike liikmetega distributiivset rindühendit (eakad mees ja naine pro eakas mees ja naine), ning nimisõnalise põhja mitmuse kasutust, kui nimisõna laiendavad rinnastatud genitiivatribuudid (Eesti ja Soome presidendid pro Eesti ja Soome president). Tegelik mitmuse kasutus ei ole neil juhtudel nii erandlik, kui tavaliselt arvatakse, ega pruugi aidata ka mitmeti tõlgendatavust vältida. Adjektiivatribuudi mitmuse kasutamist soodustavad ühelt poolt rindliikmete omadused (definiitsus - rindliikmeteks on kõige sagedamini pärisnimed; terviku osaks olemine - rindliikmetel on sageli mingi ühisnimetaja). Teiselt poolt soodustavad mitmuse kasutust ka atribuudi omadused (kvantitatiivsus; verbilisus sageli on mitmuses oleviku partitsiibid). Rinnastatud atribuutide põhja mitmus esineb valdavalt definiitsete, pärisnimeliste atribuutide korral.
\end{abstract}

Võtmesõnad: eesti keel, süntaks, nimisõnafraas, rinnastus, atribuut, arvuvorm

\section{Sissejuhatus}

Nimisõnade rindtarind on neid konstruktsioone, millel nimisõnafraasis põhjaks olles on probleeme oma laiendi arvuvormiga (a), laiendiks olles aga põhja arvuvormiga (b).

(a) eakas mees ja naine või eakad mees ja naine

(b) Eesti ja Soome president või Eesti ja Soome presidendid

Seniste suhteliselt väheste ja põgusavõitu käsitluste järgi (nt Valgma, Remmel 1968: 204; EKLP I 1974: 266-267, 434-435; Mihkla, Valmis 1979: 102, 145-146; Tauli 1980: 281-282; AK 2000: 81-82; EKK 2007: 520-521) peaksid nii ainsuslike liikmetega rindtarindi ühine omadussõnaline täiend kui ka genitiivatribuutidest koosneva rindtarindi ühine põhi üldreegli kohaselt olema ainsuses. Mitmus on erand, mida väidetavalt kasutatakse mõnel juhul mõtteselguse pärast. 
Rindtarindist põhja korral näidatakse mitmuse kasutamisega, et omadussõnaline atribuut käib tõepoolest mõlema rindliikme (või siis kõigi) kohta (eakad mees ja naine ütleb, et eakas pole üksnes mees, vaid ka naine). Samas ei saa mõtteselguse põhimõtet siin sugugi mitte alati rakendada. Tõenäoliselt tõrgub üsna paljude keel ütlemast nt väikesed maja ja aed, isegi kui selguse pärast tahaks.

Rindtarindist atribuudi korral väidetakse ühelt poolt seda, et põhja ainsus jätab harilikult ebamääraseks, kas atribuudid osutavad ühele ja samale objektile (koosvaatlev tõlgendus) või eri objektidele (eraldivaatlev tõlgendus), mitmus aga on ühemõtteliselt eraldivaatlev. Nt lausest Koosolekule kutsuti ka Võru ja Põlva esindaja ei selgu, kas koosolekule kutsuti kahe linna ühisesindaja või kummastki linnast oma esindaja, lausest Koosolekule kutsuti ka Võru ja Põlva esindajad aga järelduvat, et tegemist on eri esindajatega. Teiselt poolt aga väidetakse, et eraldivaatleva tõlgenduse korral näitab põhja ainsus, et kumbki atribuut käib ühe objekti kohta (nt üks Võrust, teine Põlvast), mitmus aga osutavat, et kumbki atribuut käib mitme objekti kohta (nt nii Võrust kui ka Põlvast kaks või rohkem). Tegelikult ei ühesta mitmuse kasutus midagi. Ühelt poolt võib ka mitmusel olla koosvaatlev tõlgendus (nt mitu ühist esindajat Võrust ja Põlvast). Teiselt poolt ei pruugi mitmus eraldivaatleva tõlgenduse korral sugugi osutada ainult kummastki mitmele. Tõlgenduse ühestavad keelevälised teadmised, kontekst, vahel ka lausesisesed asjaolud, nt öeldisverbi vorm (kui rinnastatud atribuutidega nimisõnafraas on lause alus, siis ainsusliku öeldise korral on tõlgendus ühemõtteliselt koosvaatlev, nt Võru ja Põlva esindaja osales terve päeva, vrd osalesid).

Siinses kirjutises püütakse tuua pisut lisaselgust nende tegurite kohta, mis tegelikult tingivad mitmuse kasutust kõnealustes konstruktsioonides. Esmalt vaadeldakse adjektiivatribuudi mitmuse kasutust rindtarindist põhja korral, seejärel põhja mitmuse kasutust rindtarindist genitiivatribuudi korral. Analüüsitav keelematerjal on põhiosas hangitud etTenTenkorpusest (http://www.keeleveeb.ee/), mis sisaldab mitmeid keelevariante, ning Tartu Ülikooli eesti keele koondkorpuse ajakirjanduse allkorpusest ${ }^{1}$ : ajalehtedest Postimees (1995-2000), Eesti Päevaleht (1995-2007) ja Õhtuleht (1997-2007).

1 http://www.cl.ut.ee/korpused/kasutajaliides/index.php?lang=et, näidetes tähistatud [A]. 


\section{Rindtarindi mitmuslik adjektiivatribuut}

Kui nimisõnafraasi tuumaks on rindtarind, mille ühendavalt seotud ainsuslikeks liikmeteks on abstraktnoomenid vm kvantitatiivselt piiritlemata nimisõnad, või kui rindpõhjaga tarind esineb liigitava öeldistäitena, siis enamasti atribuudi arvuprobleemi pole. Nende ühine adjektiivatribuut on üldjuhul ainsuses.

Välisminister Urmas Paeti sõnul on ELi-USA suhetel otsene mõju ELi konkurentsivõimele maailmas ning üleilmsele stabiilsusele ja heaolule. [etTenTen] Sõjalistel eesmärkidel kasutatav tehnika ja teadus annab ideoloogiate poolt õhutatud vihkamise kätte otsustava relva. [etTenTen] Igapäevaselt ta alkoholi ei tarbi, on suurepärane abikaasa ja isa .. [etTenTen]

Ainsuse või mitmuse probleem kerkib siis, kui rindliikmetel on piiritletud (loendatavad) referendid. Domineerib küll ainsus. Ainsusliku atribuudi korral langeb rindtarindist tuumosaga nimisõnafraas kokku nimisõnafraaside rindtarindiga, kus täiend kuulub üksnes esimese substantiivi juurde.

Tal on väike maja ja aed.

Tõlgendus 1: Tal on väike [maja ja aed]

Tõlgendus 2: Tal on [väike maja] ja [aed]

Tõlgenduse 2 korral atribuudi vormiline ja sisuline ühildumine ühtivad, sest ühildumist kontrollib üht objekti tähistav ainsuse vormis moodustaja. Mõlemat rindliiget hõlmava 1. tõlgenduse korral on seevastu tegemist vormilise ühildumisega, sest sisulise ühildumise korral peaks omadussõna mitmuses olema, nii nagu öeldisverb rindtarindist aluse korral (nt Maja ja aed asusid äärelinnas). Adjektiivatribuudi arvuvormi määrab talle lähima rindliikme vorm. See nähtub hõlmava atribuudiga rindtarindeist, mille üks liige on mitmuses, teine ainsuses.

Ostsin uue [ülikonna ja kingad]

Ostsin uued [kingad ja ülikonna]

Ehkki Tal on väike maja ja aed -tüüpi konstruktsioonide puhul on tegemist vormilise ühildumisega, on sellel siiski ka teatav sisuline taust. Ainsusliku atribuudi korral ei käsitata järelliiget eesliikmega päris samaväärsena, samal määral tähelepanu vajavana. Selle määramine, kas täiendiga 
väljendatu käib ka järelliikme kohta, jäetakse konteksti hooleks, mis aga tähendab võimalust, et see jääbki ebamääraseks.

Adjektiivatribuudi arvuühildumise vormilisus on kooskõlas keeletüpoloogiast tuntud põhimõttega - mida väiksem on süntaktiline (struktuuriline) distants ühilduva moodustaja (sihtmärgi) ja ühildumisallika (kontrollija) vahel, seda tõenäolisem on süntaktiline (vormiline) ühildumine (Corbett 1979, 2000). Adjektiivatribuut ja selle põhi kuuluvad ühte ja samasse fraasi, kuid näiteks alus ja predikaatverb mitte. Adjektiivatribuudi arvuühildumine on seetõttu vormilisem kui verbi arvuühildumine, mis avaldub just mitteprototüüpse ühildumise kontrollija korral, nagu seda on rindtarind. Verbi arvuühildumine on omakorda vormilisem kui öeldistäite arvuühildumine (sest nt kui aluseks on viisakust väljendav teie, siis öeldisverb on mitmuses, öeldistäide aga ainsuses - Juhan, te olete nii tubli!) (Erelt 1999, 2000).

Erinevused eri lauseliikmete ühildumise süntaktilisuses või semantilisuses on astmeerinevused, mitte ja/ei-erinevused. Nii leidubki ainsuslike liikmetega rindtarindite puhul peale adjektiivatribuudi vormilise ühildumise siiski ka sisulist ühildumist, s.o mitmuslikku atribuuti. Rindtarind käitub niisugusel juhul nagu mitmuslik nimisõna, väljendades võrdväärsetest osadest koosnevat distributiivset tervikut.

Mitmusliku atribuudiga ainsuslikud rindliikmed on harilikult definiitsed. Suhteliselt sageli esineb mitmust ainsuse asemel pärisnimeliste rindliikmete korral, nt ajakirjanduskorpuse pistelises väljavõttes oli 42 pärisnimede rindühendi (mittepartitsiipne) atribuut mitmuses 26 juhul.

Tulevastel põlvedel jääb küll teadmata, et just suvel 1997 käisid neid kive kaemas muidu graffiti-lembesed Jüri ja Mari .. [A] Kaheksa 10-19 koha võrra positsiooni parandanud riigi seas olid ka loodusvarade poolest rikkad Venemaa ja Kanada. [A]

Teine silmahakkav asjaolu on rindliikmete tavalisest suurem ühtekuuluvus. Elli Riikoja on väitnud (EKLP I 1974: 267), et „Mitmuslik atribuut tagab mõtteselguse ka juhtudel, kui ta laiendab üht mitme täiendiga ainsuslikku põhisõna. Näit. Eelmise paragrahvi tarbetud 3. ja 4. punkt jäeti ära. Liiga pikad teine, kuues ja seitsmes peatükk tuleb ümber töötada. Autahvlile kanti eesrindlikud „, Koidu“, Eduard Vilde nimeline ja Aruvälja kolhoos". Lisatagu siia veel üks näide. 
Lisaks sarja 12. kohale saavutas Klettenberg hobusel Terror veel ka erinevates parkuurides auhinnalised 5. ja 6. koha. [etTenTen]

Need näited juhivad tegelikult tähelepanu sellele, et adjektiivatribuudi mitmust võimaldavaks asjaoluks on see, et rindliikmete referente saab käsitleda ühe terviku (hulga) osadena ja sellisena on neil mingi ühisnimetaja (punkt, peatükk, koht, kolhoos jne).

Tervik või ühisnimetaja paistab läbi ka paljudest nendest mitmusliku täiendiga konstruktsioonidest, kus seda otseselt nimetatud pole. Sageli on seesugused rindühendid (mingis kultuuris) tüüpiliselt ühtekuuluvaid mõisteid väljendavad ühendid, mida on nimetatud ka loomulikeks (ingl natural) rindühenditeks (Wälchli 2005; Dalrymple, Nikolaeva 2006), nagu ema ja isa (= vanemad), mees ja naine (= inimesed), kass ja koer, keha ja vaim jms.

Kallid ema ja isa (= vanemad), parimad soovid teile New Yorgist. [A] Ei ole nad teatrikummitused, vaid sümpaatsed mees ja naine .. [A]

Näiteks pisteline väljavõte ühendi ema ja isa kohta sisaldas 7 mitmusliku ja 7 ainsusliku atribuudiga näidet (arvestamata kvantitatiivse ja partitsiipse atribuudiga ühendeid).

Kuid pärisnimedegi puhul, kus sellist sisemist (kultuurisidusat) loomulikku ühtekuuluvust pole, eeldab ühisatribuudi mitmus tavaliselt mingit ühisnimetajat. Niisugusel juhul on tegemist olukorra- või kontekstiterviklikkusega.

Armsad Leelo ja Mare! = Armsad sõbrad (kolleegid vms) Leelo ja Mare! .. kogunemine, mis seekord sai toimuma Sae külas, Hiiekalda talus, kus meid tervitasid lahked Jana ja Riho Kokk. [etTenTen]

Atribuudi arvuvorm oleneb ka atribuudist endast. Tihtipeale on mitmuses atribuudid, mis väljendavad otseselt või kaudselt kvantiteeti. Arvukalt näiteid on küll peamiselt vanuse kohta.

Prefektuuri toimetati Valgast pärit 16-aastased Jüri ja Aleksandr. [A] Läinud reedel pöörasid Pajusi vallas ühes talumajas tülli keskealised Jüri ja Тiiu. [A]

Elli Riikoja (EKLP I 1974: 266) ning temast lähtudes ka Valter Tauli (1980: 282) on juhtinud tähelepanu mitmuse kasutusele ka siis, kui adjektiivatribuudiks on $v$-või tav-kesksõna, nt Üleval mägedes viibivad Allikja Raudsepp otsustasid laskuda alla laagrisse. See mitmuse kasutus väärib 
tõesti eraldi esiletoomist. Siinses väljavõttes sõnapaare mees ja naine, isa ja ema jt laiendav leksikaalselt adjektiveerumata $v$-partitsiip (tav-partitsiipi korpusnäidete hulgas ei leidunud) esines mitmuses 23 juhul 39-st. Märkimisväärne on seejuures, et peaaegu eranditult (21 juhul) esines mitmuslik atribuut subjektilise rindtarindi laiendosana (a). Ainsuslikku partitsiipatribuuti kasutati seevastu valdavalt mittesubjektilise rindtarindi korral (b).

(a) Rahvamassis truult teineteise kõrval seisvad, vooluga kaasa liikuvad Jaan ja Ilme tahavad ühise deklaratsiooni esitada, kuid ei tea, kuidas seda teha. [A] Abrukal elavad isa ja poeg kukkusid laupäeva pärastlõunal teel koju läbi õhukese merejää. [A]

(b) Vangistatud on Eestist pärit vene keelt kõnelev mees ja naine. [A] Jehoova tunnistajate usulahku kuuluva ema ja isa puhul kaalutakse, kas anda nad kohtu alla süüdistatuna omaenda lapse surma põhjustamises ettevaatamatuse tõttu [A] .. nende all peab Kaie silmas oma elukaaslast ning naabruses elavat ema ja isa.

Nii rohke mitmuse kasutus kesksõnalise atribuudi puhul on ilmselt seletatav kesksõna verbilisusega (sündmuslik sisu, ajasuhte väljendamine, verbile omaste laiendite olemasolu). Suuremast verbilisusest võib tuleneda ka verbile omaste ühildumisreeglite suurem rakendumine, s.o sisuline ühildumine rindtarindist subjekti korral. Oleviku partitsiip langeb pealegi vormilt kokku oleviku mitmuse 3. pöörde vormiga.

\section{Rinnastatud täiendite mitmuslik põhi}

Nagu juba öeldud, on eesti keele üheks süntaktiliseks erijooneks peetud sedagi, et nimisõna jääb ainsusesse ka siis, kui seda laiendavad eraldivaatlevad rinnastatud täiendid, s.o täiendid, millest igaüks osutab eri üksikobjektile.

uus ja vana maja, mitte: uus ja vana majad naise ja mehe keha, mitte: naise ja mehe kehad Munga, Gildi ja Rü̈̈tli tänav, mitte: Munga ja Rüütli tänavad

Adjektiivatribuutide korral pole põhja ainsuse erandituses kunagi kaheldud, genitiivatribuutide puhul on mitmust siiski mõnel juhul võimalikuks peetud. Karl Mihkla arvates (EKLP I 1974: 434) on mitmus võimalik peamiselt siis, kui põhisõna väljendab mõne täiendiga seoses mitut. Nt 
lausest (a) nähtuvat, et mõlemast linnast oli saabunud mitu võistkonda, lausest (b) aga, et kummastki linnast oli üks võistkond.

(a) Võistlustele olid saabunud Tallinna ja Tartu võistkonnad.

(b) Võistlustele oli saabunud Tallinna ja Tartu võistkond.

Samuti on mitmuse kasutust peetud loomulikuks juhul, kui rinnastatud atribuutide loetelu lõpus on mitmuslik lühend jm, jms, jt, jts, vm, vms (Aavo Valmis: Mihkla, Valmis 1979: 145-146; Valter Tauli 1980: 281-282).

Ta oskab vestelda eesti, vene, saksa, inglise jt [ja teistes] keeltes.

Tauli on olnud mõnevõrra teistest liberaalsem, pidades mitmust ainsuse rööpvõimaluseks järelatribuutide korral.

Ma võtsin telefonikõne(d) Tallinna ja Tartusse. Ma mõtlen koosolekut/ koosolekuid enne jõulu ja uue aasta algul.

Samasugune ainsust soosiv suhtumine, mis lähtus Matti Sadeniemi (1960) seisukohtadest, valitses pikka aega ka Soome keelekorralduses, kuni 1988. aastal avaldas Marja Lehtinen ajakirjas Kielikello artikli, mis näitas veenvalt, et mitmusliku põhja kasutus rinnastatud täienditega konstruktsioonides on tegelikkuses tunduvalt ulatuslikum, kui seni arvatud, lausa valdav. Näiteks ajalehetekstide 150st genitiivsete pärisnimeliste atribuutidega konstruktsioonist olid tervelt 139 mitmusliku põhjaga. Suures soome keele grammatikas (ISK 2004) on astutud veel samm edasi ning peetud ainsuslike genitiivatribuutidega konstruktsioone, mille põhi on ainsuses (nt verotuksen ja työelämän uudistus), üksnes koosvaatlevaiks, st ühele tervikule osutavaiks.

Kes vähegi kõnealust tüüpi konstruktsioonide kasutust on osanud tähele panna, see on arvatavasti märganud, et ka eesti keeles on mitmust rohkem, kui normatiivsetes grammatikates soovitatud. Kindlasti ei kehti Mihkla piirang. Mitmust ei kasutata küll mitte nii palju kui soome keeles, rääkimata vene keelest, kus põhi on mitmuses ka rinnastatud ainsuslike adjektiivatribuutide korral, nt старый и новый дома, kuid siiski mitte nii vähe, et seda erandiks pidada.

Ka rindtarindist atribuudi korral oleneb põhja mitmuse kasutus ühelt poolt põhjast ning teiselt poolt atribuudist. Mitmuse kasutuse eelduseks on põhjaks oleva substantiivi kvantitatiivne piiritletus. Kui põhjaks on abstraktnoomen (meeleolu, tähtsus, majandus, poliitika, tegevus jne) või muu kvantitatiivselt piiritlemata substantiiv, mida tavaliselt mitmuses ei 
kasutata, siis jääb see ka rinnastatud adjektiivatribuutide põhjana üldjuhul ainsusesse.

Raamatukogus olevad materjalid on keskendunud peamiselt Eesti, Läti ja Leedu ajaloole, folkloorile ja etnograafiale. [A] Läti ja Itaalia tähtsus Eesti impordipartneritena suurenes eelmise aastaga võrreldes veelgi .. [A] .. Eesti, Läti ja Leedu majanduspoliitika püsib erinevana .. [A] Kutsume kõiki lapsevanemaid, pedagooge, kooli ja lasteaia personali .. Misso valla hariduse ümarlauale [etTenTen] .. kui lisada veel töötukassa ja haigekassa raha, siisei jää majandusimest küll midagi järgi. [etTenTen]

Piiritletud põhja korral oleneb mitmuse kasutus rinnastatud atribuutide referentsuse astmest. Põhja mitmus on kõige tavalisem definiitsete genitiivatribuutide korral. Tüüpiline mitmuslikku põhja laiendav rindtarind koosneb pärisnimedest.

Eesti ja Soome välisministrid kirjutasid kolmapäeval Helsingis alla koostöömemorandumile .. [A] Eesti ja Soome valitsused on Rootsile teatanud, et nad ei poolda surnukehade ülestoomist ja soovivad endiselt jätta Estonia vrakk puutumatuks paigaks. [A] Operaatorlepingu igal lehel on Jaak Tamme ja TSM-i juhatuse esimehe Einar Vettuse allkirjad. [A] Kolm ööd-päeva töötanud piirivalve ja politsei operatiivtöötajad said relva kätte järgmisel õhtul Sepa ja Maleva tänavate nurgal asuvast katlamajast, kuhu röövlid selle peitsid. [A] Setumaa valdade liitu kuuluvad Mikitamäe, Meremäe, Värska ja Misso vallad. [etTenTen] Rahvusvahelise turniiri avamängus kohtusid Paide Ühisgümnaasiumi staadionil Horvaatia ja Malta koondnaiskonnad. [etTenTen]

Seniste normatiivsete arusaamade järgi peaks kõigis neis näidetes olema põhisõna ainsuses. Mõistagi esineb ainsust praegugi.

Eesti ja Soome välisminister allkirjastavad kahepoolse viisavabaduse lepingu kolmapäeval Tallinnas .. [A] Eesti ja Soome valitsus kinnitasid eelmisel nädalal, et „Estonia“ vrakk ja seda ümbritsev ala on laevahuku ohvrite viimne puhkepaik. [A] Rootsi ajal olevat samal kohal, Laia ja Rüütli tänava nurgal, asunud õuekohus. [A] Setomaa Valdade Liidus, kuhu kuuluvad Misso, Meremäe, Mikitamäe ja Värska vald .. [etTenTen]

Kuid mitmuse ja ainsuse arvuline suhe on pärisnimeliste liikmetega rindtarindi puhul enam-vähem võrdne, mistõttu mingist mitmuse erandlikust kasutusest rääkida ei saa. Näiteks ajaleheteksti 67 näitest, mille täiendosaks oli Eesti ja Soome ning põhjaks president, riigipea, valitsusjuht, peaminister, välisminister, siseminister, valitsus, riigikantselei, siseministeerium ja 
keskkonnaministeerium, oli põhi 33 näites mitmuses, 34 näites ainsuses. 26-st rindatribuudiga näitest, mille põhjaks oli tänav, vald, maakond, küla, alev või linn, oli põhi mitmuses 12 ja ainsuses 14 korral.

Pärisnimeliste rindtarindite põhjana võib mitmuses mõnikord olla ka tavaliselt piiritlemata (jaotatav) substantiiv, nt majandus, poliitika vms, mis sel juhul tõlgendub piiritletuna.

Analüütikute sõnul on Itaalia ja Hispaania majandused ilmselt juba languses. [etTenTen] Riigid peaksid .. regulaarselt vaatama läbi oma integreeritud planeerimise ja arendustegevuse poliitikad. [etTenTen]

Põhja mitmust esineb ka üldnimeliste rindtarindite korral.

.. möödunud neljapäeval leidis naine korterist abikaasa ja poja surnukehad. [etTenTen] Kas näiteks köögi ja vannitoa õhuklapid on avatud? [etTenTen] Analüüsides oluliste ministrikohtade jaotust valitsuses selgub aga, et KMÜ valimisliidul oli ainult peaministri ja välisministri kohad. [etTenTen] Populaarseimad olid keskkonnakorralduse ja kehakultuuri erialad. [etTenTen] Dr Peter Payne paiskas õhku küsimuse, kas teaduse ja kristluse maailmavaated on konfliktis. [etTenTen] Elementaarosakeste maailm on võrreldes meie makromaailmaga ikka totaalselt teisiti toimiv, aja ja ruumi mõisted kaotavad seal sisu. [etTenTen]

Pärisnimeliste rindtarinditega võrreldes esineb põhi siin üksikobjektidele osutavate rindliikmete puhul mitmuses siiski harva (a). Enamasti tingib põhja mitmuse juba iga atribuut eraldi võetuna (b).

(a) Traditsioonilised oskused on lugemise, kirjutamise ja arvutamise oskus. [etTenTen] Kõige suuremat huvi tunti muidugi riigikaitsekomisjoni vastu, järgnesid välisasjade, kuluseaduse ja maaseaduse komisjon. [etTenTen]

(b) Tähtajatu teenusleping sõlmitakse, kui on täidetud eeskirja ja liitumislepingu tingimused. [etTenTen] = .. eeskirja tingimused ja liitumislepingu tingimused.

Mitmust esineb ka pärisnimekujuliste genitiivsete liigiatribuutide ja neile lähedaste käändumatute omadussõnade korral (a). Liigitähenduse tõttu on sellise rindtarindi põhi siiski tavaliselt ainsuses (b).

(a) Küpros on teatavasti kahe vaenuliku kogukonna vahel jagatud saar. Ametlik lõhe kreeka ja türgi kogukondade kooselus fikseeriti aastal 1974 .. [A] Eristatakse kokku kaheksat lokaalset kultuuri: india, hiina, babüloonia, egiptuse, antiik-, araabia, vene ja lääne-euroopa kultuurid. [etTenTen] Minu ajal, kuni 1934. aasta suure koolireformini olid Petseri 
riiklikus gümnaasiumis 10 klassiga vene ja eesti osakonnad, kummaski viis klassi. [etTenTen] Keelt peab oskama ja mitte ainult inglise,väga tähtsad on ka vene ja hispaania keeled. [etTenTen]

(b) .. esindatud on ka vene ja juudi kogukond Eestis .. [A] Lõuna-Eesti on huvitav seepärast, et siin on võimalik lühikese vahemaa tõttu tutvuda eesti, vene ja läti kultuuriga .. [A] Organisatsiooni ametlikud keeled on inglise, hispaania, prantsuse, saksa ja vene keel. [etTenTen]

Korpusest ei õnnestunud leida näiteid mitmuse kasutuse kohta liitsõna täiendosade rinnastuse korral, kus oleks selgelt tegemist üksikobjektide eraldivaatleva rinnastusega, s.o juhtumeid, mille puhul kehtiks nt järgmine võrdus: majandus- ja õigusteaduskonnad = õigusteaduskond ja majandusteaduskond. Liitsõna täiendosade rinnastust saab nagu adjektiivatribuutidegi rinnastust tõenäoliselt alati käsitada nimisõnafraaside elliptilise rinnastusena, st majandus- ja õigusteaduskonnad = õigusteaduskonnad ja majandusteaduskonnad, majandus-ja õigusteaduskond = õigusteaduskond ja majandusteaduskond. Sama kehtib tuletiste kohta, nt mees- ja naiskonnad = meeskonnad ja naiskonnad, mees- ja naiskond $=$ meeskond ja naiskond.

\section{Kokkuvõte}

Nii adjektiivatribuudi mitmus rindühendist põhja korral kui ka rindühendist genitiivatribuutide põhja mitmus ei ole päris erandlik, nagu enamasti väidetakse, vaid teatud juhtudel üsna tavaline. Adjektiivatribuudi mitmuse kasutamist soodustavad ühelt poolt rindliikmete omadused: definiitsus rindliikmeteks on kõige sagedamini pärisnimed, nt loodusvarade poolest rikkad Venemaa ja Kanada; terviku osaks olemine - rindliikmetel on sageli mingi ühisnimetaja, nt auhinnalised 5. ja 6. koht, ning tihtipeale moodustavad nad pooleldi kinnistunud, nn loomulikke ühendeid, nt Armsad Leelo ja Mare! Teiselt poolt soodustavad mitmuse kasutust ka atribuudi omadused. Aribuut on sageli sisult kvantitatiivne, nt 16-aastased Jüri ja Aleksandr, või verbi omadustega, nimelt oleviku partitsiip, nt Abrukal elavad isa ja poeg kukkusid läbi merejää.

Rinnastatud atribuutide põhja mitmus esineb piiritletud põhja korral ning seejuures valdavalt definiitsete, pärisnimeliste atribuutide korral, nt Soome ja Eesti välisministrid kirjutasid alla koostöömemorandumile. 


\section{Kirjandus}

AK 2000 = Ametniku keelekäsiraamat. Õigusaktide ja muude dokumentide koostaja abiline. Justiitsministeerium. Tallinn: Juura, Õigusteabe AS.

Corbett, Greville G. 1979. The agreement hierarcy. - Journal of Linguistics $15,203-224$.

Corbett, Greville G. 2000. Number. Cambridge: University Press. http://dx.doi. org/10.1017/CBO9781139164344.

Dalrymple, Mary, Irina Nikolaeva 2006. Syntax of natural and accidental coordination. Evidence from agreement. - Language 86 (4), 824-849.

EKK 2007 = Mati Erelt, Tiiu Erelt, Kristiina Ross. Eesti keele käsiraamat. Kolmas, täiendatud trükk. Tallinn: EKSA.

EKLP I 1974 = Karl Mihkla, Lehte Rannut, Elli Riikoja, Aino Admann. Eesti keele lauseõpetuse põhijooned I. Lihtlause. Toim. Ernst Nurm. Keele ja Kirjanduse Instituut. Tallinn: Valgus.

Erelt, Mati 1999. Agreement in Estonian. - Estonian: Typological Studies III. (= Publications of the Department of Estonian of the University of Tartu 11.) Ed. Mati Erelt. Tartu, 7-46.

Erelt, Mati 2000. Arvuühildumisest tänapäeva eesti kirjakeeles. - Keel ja Kirjandus 3, 180-189.

ISK 2004 = Auli Hakulinen (päätoim.), Maria Vilkuna, Riitta Korhonen, Vesa Koivisto, Tarja Riitta Heinonen, Irja Alho. Iso suomen kielioppi. (= Suomalaisen Kirjallisuuden Seuran toimituksia 950.) Helsinki: Suomalaisen Kirjallisuuden Seura.

Lehtinen, Marja 1988. Pääsanan yksikkö ja monikko eräissä attribuuttirakenteissa. - Kielikello 1, 7-20.

Mihkla, Karl, Aavo Valmis 1979. Eesti keele süntaks kõrgkoolidele. Tallinn: Valgus.

Sadeniemi, Matti 1960. Numeruskysymyksiä. - Matti Sadeniemi. Kielenkäytön kysymyksiä. (= Tietolipas 18.) Helsinki: Suomalaisen Kirjallisuuden Seura, 78-81.

Tauli, Valter 1980. Eesti grammatika II. Lauseõpetus. Finsk-ugriska institutionen. Uppsala: Almqvist \& Wiksell.

Valgma, Johannes, Nikolai Remmel 1968. Eesti keele grammatika. Käsiraamat. Tallinn: Valgus.

Wälchli, Bernhard 2005. Co-compounds and Natural Coordination. Oxford: Oxford University Press. 


\title{
Coordinate structures as parts of a noun phrase
}

\author{
MATI ERELT
}

The article examines the use of the plural form of adjectival attributes in cases where these attributes modify a distributive coordinate structure with singular conjuncts (eakad mees ja naine 'old (pl.) man and woman' pro eakas mees ja naine 'old (sing.) man and woman'), as well as the use of the plural form of nouns modified by coordinated genitive attributes (Eesti ja Soome presidendid 'The presidents of Estonia and Finland' pro Eesti ja Soome president 'The president of Estonia and Finland'). The use of the plural in such constructions is not as rare as is commonly believed, but rather is actually quite common in certain cases. Certain properties of the conjuncts favor the use of the plural form of adjectival attributes, for instance if the conjuncts are proper names, e.g. loodusvarade poolest rikkad Venemaa ja Kanada 'Natural resource-rich Russia and Canada', or if they are parts of the same whole, e.g. auhinnalised 5. ja 6. koht 'award-winning $5^{\text {th }}$ and $6^{\text {th }}$ place'. The plural is often found in partially fixed, so-called natural compounds, e.g. Armsad Leelo ja Mare! 'Dear Leelo and Mare!' The properties of the attribute itself also play a role: attributes appearing in the plural are often quantitative in meaning, e.g. 16-aastased Jüri ja Aleksandr '16-year-olds Jüri and Aleksandr', or have verbal properties, namely the present participle, e.g. Abrukal elavad isa ja poeg kukkusid läbi merejää 'A father and son living on Abruka fell through the sea ice'.

Nouns modified by coordinated attributes appear in the plural when they are bounded and predominantly when the attributes are definite, especially proper names, e.g. Soome ja Eesti välisministrid kirjutasid alla koostöömemorandumile 'The foreign ministers of Finland and Estonia signed the cooperation memo'.

Keywords: Estonian, syntax, noun phrase, coordination, attribute, number agreement

\author{
Mati Erelt \\ eesti ja üldkeeleteaduse instituut \\ Tartu Ülikool \\ Jakobi 2 \\ 51014 Tartu \\ mati.erelt@ut.ee
}

